\title{
Brendan meets Columbus: A more commodious islescape
}

James L. Smith

Centre for Medieval Studies, University of York, York

[Published in Postmedieval, Vol.7, No.4, pp. 526-538. This is a final post-print version of the article without editorial enhancement. For the publishers' text with final pagination, please see the DOI at http://link.springer.com/article/10.1057/s41280-016-0027-x.]

\section{Abstract}

This paper proposes that we can reimagine insular literatures and medieval islescapes as commodious seas of cultural and intellectual loci that span time, culture and text alike. By moving beyond the rhetoric of insular separation or connectivity, we can see that islands connect even when medieval minds saw separation. The essay focuses on the Brendan legend and the commodious cultural 'sea of islands' that it inhabits, a space that connects the modern reader to a history of other connections, fact to fancy and the real and the imaginary. When sailing in this sea, Brendan meets Columbus, and the late medieval idea of a lost island spreads though space and time.

... telle me what mervaylles ye have seen in the grete see Ocean that compasseth al the world aboute, and alle other waters comen out of hym whyche renneth in al the partyes of th'erthe (Brendan to Barrind, Caxton's Golden Legend version, Barron and Burgess, 2002, 328).

In The Corrupting Sea, Horden and Purcell argue that the notion of a monolithic geo-cultural entity, in their case the Mediterranean, is arbitrary $(2000,15)$. Drawing on Bismarck's famous assertion that '[a]nyone who speaks of Europe is wrong - it is nothing but a geographical expression,' they break down the black box notion of a single uniform body of water, building a complex web of microecologies 
and subtle interactions between peoples and their environments. The received notions of the region that the reader may have held are dissolved—only the possibility for new connections can replace them.

In this essay I propose a more commodious notion of literary islescape, and yet this is far from simple to define. A 'sea of islands' often contradicts medieval and early modern notions of physical space, achieving a homeliness and ubiquity through culture, a rich and collaborative space that has always been with us and continues to link us across vast distances, both physical and cultural. It is a sea of intellectual islands rather than granular and isolated ideas in a sea of time. To find a theoretical analog, I turn to Epeli Hau'ofa, a strong and compelling voice in the discourse surrounding insularity. In 'Our Sea of Islands,' Hau'ofa asserts that 'We are the sea, we are the ocean, we must wake up to this ancient truth and together use it to overturn all hegemonic views that aim to confine us again, physically and psychologically' $(1993,16)$. When this postcolonial reimagination is applied beyond its context, Hau'ofa's work encourages us to forget the islands in the sea of medieval culture and to see the sea of islands in which stories connect. This is not a world in which all islands connect and there are no obstructions at all, but a place of commonality and hospitality rather than alienation. To see beyond separation, we must look at insularity through a different lens. Jonathan Hsy has proposed that a 'peregrine' mode of reading enables 'a transhistorical and cross-linguistic outlook that results in moments of wondrous estrangement from conventional disciplinary frameworks' $(2013,205)$.

In order to see the sea of islands within the late medieval and early modern oceanscape, I turn to a meta-narrative by way of case study - the reception history of the Brendan legend. Rather than focusing on textual analysis of medieval insular fiction - a task already diversely explored by Cohen et al. (2008) Sobecki (2008), Sobecki et al. (2011) and Pinet (2011), to name a few, I will instead focus on the idea of a temporal islescape, and its role in the stitching together of loci through the rich substrate of a capacious cultural medium - the more commodious ocean of the title. Within this space, distinct cultural and textual spaces merge into something that blurs conventional categories, and connects islands in the sea. 


\section{The challenges of isle and ocean}

Separation brings us together. When we talk of the gulfs between islands and ideas, we are making connections across space and time that form new relationships, permanently linking idea to idea and thinker to thinker. The ocean reveals this to be true: the putatively alienating space of the ocean is culturally constructed, and at first glance it is difficult to argue with the notion that we are not at home away from land. Indeed, we would be thinking in concert with many European civilizations were we to assert this. Yet one is making decidedly non-insular connections through the very act of arguing for insularity—discussing insularity brings with it a set of relationships and connections.

If one proposes, as Gildas did in his De excidio Britonum, that Britain is 'fortified on all sides by a vast and more or less uncrossable ring of sea,' then it is correct to assert that this statement has cultural force (Sobecki, 2008, 73). As John Gillis (2009) has argued, islands are master symbols for an inexhaustible range of things, and their symbolism has helped to shape the oceans of the world. By symbolizing, they connect, even when they argue for the impossibility of connection. The ocean participates in the dual reinforcement and disregard of insularity. We repeat a modern version of an old Christian trope, the shunning of the sea as a 'corrupting oceanography', a space to be traversed yet kept apart. By arguing for separation, the 'ambiguous merits' of the islescape enable engagement with the sea as an object of cultural interconnection rather than as a barrier (Horden and Purcell, 2000, 438).

The mentality of insular separation is far from universal, as anthropology demonstrates. For the Bajau Laut of Southeast Asia, for example, the sea is not a separator, but a home. Land is another realm in which certain necessities of human life must be acquired, but the human realm is a series of boats and houses on stilts placed upon the surface of salt water estuaries (Mack, 2011, 13). For them the Other dwells on land, and a sense of commonality is defined by the water. The coast is a border, and the land exists beyond. For Hau'ofa, '[t]he world of our ancestors was a large sea full of places to explore, to 
make their homes in, to breed generations of seafarers like themselves. People in this environment were at home in the sea' $(1993,8)$.

The question now remains as to how European insular identity in the late Middle Ages can be enriched through postcolonial insular knowledges. More importantly, how can all insular knowledges merge to enrich each other? The first step is to reconcile two alternative cultural views of the sea: one as an 'unwelcome and unwelcoming wilderness,' the other 'entirely familiar and unthreatening' (Mack, 2011, 74). It is important to begin by noting that the cultural space I depict in this essay is in many senses a sea of islands defined by intellectual colonialism. It was created through acts of appropriation, exploitation, and cruelty. This cannot be removed from the story, but in the twenty-first century, European literature can mingle with the stories of those it silenced to create a world of literatures, ideas, and worldviews that reflect the richness of global pre-modernity. The goal of our Hau'ofa-esque rethinking of ocean space should not only allow Europe to find peace with its rhetoric of insular separation and oceanic inhospitality, but also to create an ocean that is the home of all seafaring imaginations, a place — as was the case in the Middle Ages — of trade, transaction, multilingualism, and human-nonhuman interaction. As Elizabeth DeLoughrey (2007) argues, there is space for a multiethnic, transoceanic, migratory, and accommodating oceanscape to form. When medieval narrative passes into the ocean and finds 'the darksome bounds of failing world,' as Adam of Bremen did, it reaches beyond, attempting to connect (qtd in Sobecki, 2008, 98).

As Sebastian Sobecki has argued, '[w]hat has historically delimited and therefore defined insular Britons is the sea with its all-encircling boundary, the shoreline' $(2011,2)$. Boundaries are permeable, yet the encircling boundary of insular identity provides a receptacle for identity. In a world of community beyond insular delineation and oceanic separation, it is difficult to determine the limitations and affordances of 'island.' In an ecological and purely literal sense, the separating power of oceans is a key force in history. The idea of the British Isles is a form of ideological confinement, long modified through classical reception, medieval negotiation, and growing hegemony at the dawn of the early modern; one might say that Western intellectual history is addicted to insularity just as it has 
struggled with anthropocentrism, taxonomic fallacies, and a tendency toward binaries. The legacies of insular addiction haunt the present for, as John Gillis argues in the context of colonialism in the Pacific, '[f]or [Europeans and Americans] the sea was a void rather than a place ... [f]or them the Pacific isles were not only spatially but temporally distant' $(2007,21)$. Medievalists have repeated this notion while in search of novelty, a salient example being the assertion that 'Islands and cities have several important features in common: they consist of bordered places with a definable inside and outside; they provide a sense of commonality for the inhabitants; and they form a barrier against the Other' (Grafetstätter, 2011, 7).

Those from a Western background are so steeped in a distinct insular worldview that the separation of islands seems self-evident. Connections are fleeting, however profound, and barriers are the norm. The ocean carries the traveler from isle to isle, but it is not home. As in the case of Bismarck's Europe, this is a geographical expression, for anyone who speaks of islands is wrong. Separation is a matter of perspective. When one set of eyes sees an inhospitable gulf peppered with self-contained spaces, another might see a space of shared ideas in which islands float like clumps or whorls of meaning in larger patterns. We should not forget that the isolation of islands has shaped their unique symbolism and cultural resonances, and yet separation is a discourse of connectivity. Separateness connects across space and time through the stories that we tell, and the insular recedes. I do not propose replacing the isolation of islands with the universal connection of islands, as Matthew Goldie's survey of island theory cautions $(2011,9)$. Instead, it is more accurate to say that the rhetoric of insular separation creates part of a new and rich network of connections, some formed from the discussion of separateness itself.

This essay is by no means an argument that medieval barriers within oceanic space - the impassable oceanus dissociabilis or the boundary of the litoral-lack power, but that ideas of limitation or transaction are themselves a form of transaction, communities of ideas of community and separateness in dialog (Sobecki, 2008, esp. 16-24). Rather than succumbing to forces of what Hau'ofa calls 'belittlement' of mentality, what might a medieval insular identity—or collection of identities- 
look like after undergoing a 'world enlargement' enabled by the mediating polis of the ocean (1993, 6)? Simone Pinet argues that insular fiction is a set of possible itineraries between islands, a grouping process for the emphasis of themes such as ontology, politics, or ethics $(2011,155)$.

The power of world enlargement has been writ large upon world history discourse by Janet Abu-Lughod's (1989) seminal monograph Before European Hegemony. By exploring a pre-European network of trade circuits spanning the Mediterranean, Arabian, East African, Indian, and Asian coastlines of the Indian ocean, Abu-Lughod revealed a lively system of cultural transaction and unimagined wealth, a world in which Europe was a peripheral node of a vast system centered on the Indian Ocean. Only with the fourteenth-century colonial degradations of the Portuguese in East Africa did this system disintegrate. In her conclusion, Abu-Lughod reflects that '[w]orld systems do not rise and fall the same way that nations, empires, or civilizations do. Rather, they rise when integration increases, and they decline when those boundaries contract' $(1989,367)$. To my mind, the same process occurs trans-temporally: world systems decay within the historical imagination when links are forgotten and grow when integration is remediated.

\section{Saint Brendan and Christopher Columbus meet in the sea of islands}

From the early Middle Ages until the turn of the fifteenth and sixteenth centuries, the long-adapted tale of Brendan and his monks sailing beyond the familiar shore of Ireland into a realm of divine barriers and cultural connections provided meaning to generations of readers. It was a farrago of popular medieval tropes and cultural idioms studded in an imagined ocean: eschatological symbolism, topoi of Biblical legend, abundant marvels, and interconnected stories of moral behavior to be read by itineraries of travel. The legend exhibited tremendous longevity, creating a teeming cultural ocean-home of familiar yet alien marvels, meaning interpreted and re-interpreted, and-after many centuries of this process - a bold vision of Christian salvation in the fevered imagination of one late medieval mind, that 
of Christopher Columbus. As a medieval literary and (multi)cultural entity, Saint Brendan's isles have connected and expanded across the barrier-sea of mythic and topographical distance.

Insular fictions are not only about islands connected spatially or geographically, but also about temporal connection. The Brendan texts participate in constellation of words, ideas, and adaptations that are themselves a sea, connected across time despite existing as a collection of distinct nodes. To read them is to float in a Hau'ofa-esque world of journeyings, forays, stories, itineraries, and obsessions. As we will see, the navigation of this commodious ocean-defined more by what it connects than by what it divides — spans centuries, crosses cultures, and provides a substrate by which ideas float from era to era like flotsam and jetsam, washing up on distant shores. The islands of this world are textual and cultural entities, distinct in and of themselves and yet porous and ecologically entangled. They are not universally connected, and indeed many of their interactions are predicated upon a rhetoric of alienation or impassability. We, the readers of the Brendan text, are this sea, and it is us. So are all of those who have traversed the spaces between their far-flung contexts.

The medieval cultural translation and reception history of the Brendan legend is explored within Barron and Burgess' 2002 critical edition, spanning the period from the eighth-century Latin Nauigatio Sancti Brendani abbatis to the age of print with Caxton's 1484 edition of the Golden Legend of Jacobus de Voragine. Originating with a precursor to the Irish Immram Máele Dúin and passing into the protoNauigatio, the story of Brendan generates the Voyage and mature Nauigatio versions, and floats through the entirety of the Middle Ages. The tale has a rich and varied stemma that reaches every corner of European imagination like a cultural wake (Strijbosch, 2000, 204-205). As the tale of Brendan meandered through centuries, it glides through Europe's rich multilingualism, with versions of the tale - in its diverse forms - appearing in Latin, Anglo-Norman French, Dutch, German, Italian, Occitan, Catalan, Old Norse, and in Middle English in the South English Legendary and Golden Legend.

The Brendan tradition connects as it withdraws, the endless retelling of the story both emphasizing the inaccessibility of the wondrous isles encountered by the Saint and his monks while 
constantly making new cultural, linguistic, and scriptural links. It spreads across time and bridges space while loudly arguing that certain places cannot be touched. It places the reader in touch with the divine while severing the bond. Its connections ensnare generations of readers and scholars, fueling their obsessions. The lure of the legend is captured by the editors in their introduction, in which they highlight the historical appeal of the tale:

From Columbus to Tim Severin [seekers of Brendan] were drawn to follow in his wake, often in search of self as much as foreign shores. What matter if Brendan never went where they followed him, so long as he lured them on from land to new-found land. As he has passed from island to island, so the legend passed from age to age, bringing to each the meaning of which it was capable, literal or metaphorical (Barron and Burgess, 2002, viii).

The multi-textual legend of Saint Brendan makes a rhetorical virtue of separation from the object of its desire, the Promised Land of the Saints. The fifteenth-century Book of Lismore states that Brendan asked God to 'give him a land secret, hidden, secure, delightful, separated from men' (as cited in Barron and Burgess, 2002, 6). The desire for peregrinatio pro amore Dei motivates the narrative, yet the reality is a sea of islands visited in turn, the manifold itineraries highlighted by Pinet. The historical and allegorical content form a rich tapestry of interactions — cultural, temporal, linguistic — evident in the manifold translations of the late Middle Ages. The islescape is held together by currents of connection that reach across literary history, that are multiple and migratory, fleeting and fluid. Interpreting the logic of these nebulous motions requires an escape from the Western dialectic obsession with a single, authoritative conclusion or interpretation reached by the reasoned defeat of 'lesser' arguments. Rather, we could favor what Barbadian poet Kamal Braithwaite has described as 'tidalectics,' in which a successful logical outcome is reached by radiating from the center and then back again rather than following a linear path of attack (ctd in Shell, 2014, 20-21). Tidalectics circulate rather than circumscribe. Following a circular path of ebbing and flowing reason, we can freely navigate the internal logics of out literary islescape without the need for a definitive outcome, passing across time and space and back again to do so. 
A tale that was endlessly received and adapted is framed within the Nauigatio tradition as the next step in a further chain of receptions of paradisal knowledge stretching back through the ages, presumably to Adam and Eve themselves. Within the tradition of the Nauigatio, the story of Saint Brendan's voyage begins with marvelous knowledge gleaned from a prior report. In the Nauigatio, Abbot Barrind visits Brendan and his fellow monastics at Clonfert, and relates a tale of discovery. In the tale, he and the monks of Abbot Mernoc sailed from the remote monastic community of the Delightful Island, visiting the Promised Land of the Saints and returning with the scent of paradise still infused into their clothes (Nauigatio, Barron and Burgess, 2002, I, 26-27). It is this tale that inspires Brendan and his fourteen brothers to seek the isle in the distant ocean. This isle remains ever-present in the spiritual imagination of the faithful despite hiding within the wide sea.

In the twelfth-century German vernacular Reise-fassung (journey version) of the legend, the story begins with another book, encountered by Brendan and his monks at the outset (Matthews, 2016, 57; Strijbosch, 2000, 4-5, 8). In this version of the story, Brendan reads a marvelous report that there are two paradises on earth, three heavens, a location where there is day when the reader has night, a giant fish carrying a wood on his back, and a place where Judas enjoys God's mercy every Saturday night. Brendan refuses to believe what he has read unless he has seen it with his own eyes and burns the book in anger. An angel informs him that he must travel at the command of God to ascertain for himself what is truth and what is falsehood, sailing for nine years in order to rewrite the book and discharge his debt. Since his lack of faith has destroyed the wondrous text, he must recreate it, rewriting the islescape on the surface of medieval consciousness. He passes from quotidian life and into legend, going out to sea and eventually returning to Ireland with potent partial knowledge. The book that he is tasked to write, like the book in which he is written, is part of a greater trans-temporal pattern of intellectual wanderings within the sea of islands. Like the Reise Brendan, the textual history of the legend is an endless process of partial erasures, imperfect re-inscriptions, emotional reactions, and endless interpretations. 
Despite a complex rhetoric of inaccessibility and accessibility, the many medieval versions of the tale begin with the premise that nothing is truly disconnected from anything else by time or space, but only the will of God can determine what is hidden and what is revealed, what is known and what is prohibited. In the Caxton version, Brendan and his monks are greeted by the glorious sight of the promised land, 'the fayrest contre eestward that ony man myght see.' They cannot reach it, for it is separated from them by a stream that they dare not cross. A young man comes to them, and admonished them to 'be ye now ioyeful,' for they have reached the end of the temporal world, and 'thys water that thou seest here departeth the world a sondre, for on the other syde of thys water may no man come that is in thys lyf.' This final barrier bars all travel for Brendan, who is advised that he 'shalte sayle ageyn in to thyn owne contree,' knowledge concealed until the appropriate time and place of apprehension (Caxton's Golden Legend, Barron and Burgess, 2002, 342). Brendan's journey is over, his temporal limits defined, and yet the islescape of the Brendan legend teems with intellectual life that passed beyond the barriers of the world: it spreads from text to text, is transcribed and adapted, is retranscribed and translated, passed from culture to culture, from scribal production to the printing press. It continues to haunt us today.

The spiritual and cultural ocean that it reveals is equally hospitable to thought, with even the inaccessibility of a time, a space, a fact opening up a new accessibility. When the monastic seeks herimum in oceano (a desert in the ocean), they can never leave the world behind as long as their story is told (Sobecki, 2003 199). Like a stylite upon his pillar accosted by admirers or a remote hermit visited by pilgrims, the seeker of an isolated religious life cannot escape. His assertion of separation ensures his part in the story, and so it is for the Brendan legend itself. By following the lead of Hsy and taking a step back from the frame of the narrative, we see that the insular identity of the British Isles and the wider European world it connected to was far from limiting. When one reads from a distance, flying above the spaces within the text, the ocean appears as the cultural medium by which loci of power, be they moral, temporal, or topographic, are bonded together. Hsy's peregrine reading takes the interpreter 
soaring through the tangles of the Brendan legend, with the occasional sojourn on a distinct historical and cultural isle within the sea.

At the end of the fifteenth century, Brendan continues to explore the cultural sea of islands and meets Christopher Columbus, so to speak, passing on the blessing-or curse, given Columbus' notorious megalomania — of insular obsession. Brendan's tale, along with a mélange of other classical, medieval, and late medieval texts, shaped a worldview that would have profound effects on the coming centuries. The tale of Brendan's legendary isle passed into received wisdom, haunting the imagination of early transatlantic voyagers as they sought to traverse the Western ocean beyond the pillars of Hercules. Having failed to find the wonders they sought in more immediate Azores or Canaries, late medieval minds pierced the space beyond the shore, expecting a sea of familiar tropes mapped upon the forbidding face of the Atlantic. Their heads filled with visions of lost islands in the hidden sea, European minds such as that of Columbus were never culturally isolated as they ventured away from shore. As the late Middle Ages infused the imagination of Columbus and his contemporaries, so too did the everelusive promised land continue to elude explanation. In his writings on the Third Voyage, Columbus writes with a certain fanatical zeal that 'I entered upon a new voyage to a new heaven and a new earth, which up to then had lain hidden' (Third Voyage, ed. Jane, 1988, 2.50). New, but also part of a vast mass of old things. Columbus attempted to pierce the veil of unknowing, making a logical interpretation of a wave-washed string of linked ideas spread across a fluid space in which linearity and singularity were meaningless. Tidalectic reasoning won out, and his reports were as mythical and multiple as the legends that lured him across the sea. The Spanish grandees back at home were thrilled but confused, in equal measure.

The influences of medieval ideas on Columbus and his contemporaries were many and powerful. This was especially true of the islands he imagined beyond the horizon but which were close in cultural terms, intimately so. Valerie Flint makes a strong case for the influence of imagined islands $(1992,87)$. Antilia was one of the most well-known, 'the Isle of the Seven Cities' that appears on many fifteenth-century maps and was supposedly inhabited by the descendants of Visigothic Christians 
fleeing the eighth-century Islamic conquest of Iberia. The Isle of Saint Brendan also features repeatedly, a fabled destination still popularly believed in fifteenth-century Spain. It is commonly known that Columbus sought the isles at the Far East of medieval accounts and maps, the East Indies of the mind that became the West Indies instead. His fondness for Pierre d'Ailly and his 1410 Imago Mundi populated the Atlantic with an expanded islescape of legend, paradisal imagining, and eschatological aspiration — d'Ailly, like Brendan, dreamed of the isles of the Blessed. When Westerners peered beyond the horizon, the next mystery was always waiting to be glimpsed. Flint lists many other appealing factors of the legend:

Much of the [Brendan] story was to the taste of Columbus, from the renunciation of home and kindred (with its attendant rewards) to the Christian prophecies fulfilled and assured of fulfillment. The Navigatio may well occupy an especially crucial place in Columbus' medieval cosmology (Flint, 1992, 97).

Many of the late medieval maps that Columbus would have had access to take the existence of the isle(s) as fact, marking them clearly. The 1367 portolan chart produced by the Venetian cartographers Domenico and Francesco Pizzigano clearly marks the Isle of Saint Brendan, stating that it was reached in 565 by Brendan and his brothers (Flint, 1992, 97). Newfoundland, the Antilles, Iceland: the list of potential candidates was long. The cartographers, encyclopaedists, and explorers of late medieval Europe were ever reaching out and colonizing the Atlantic with their imagination, just as others turned to the East and filled the lands beyond the Levant with monsters and marvels. The physical barrier of the ocean was no impediment to storytelling, nor was the barrier of time. The rhetoric of an adversarial relationship with the inhospitable sea is far from a complete rendering of the late medieval reality, failing to capture its rich interconnections. The caesurae and barriers remained, but their existence was part of the story. The temporal islescape that Columbus crossed in his fancy took him to the Americas before he ever set sail, separations and all. He did not find Antilia or Brendan's isle, for they hid behind the intellectual horizon like the Amazons or the Cynocephali of the East. One could even say that 
Mandeville traversed a sea of islands of his own. The fact that land replaced water and cities, that marvels and monstrous nations replaced islands, was largely irrelevant.

In many cases, insular interconnections and divisions were colonial in nature, the mapping of medieval imagination onto a perceived tabula rasa. The temporal sea of subtle connection was parted by a straight path of progressivism, Christian supremacism, and unilineal cultural evolution. This trend has continued into the present in a seemingly innocuous form: the impulse to explain the voyage of Saint Brendan as an act of fact-based proto-exploration rather than a cultural artifact. Rather than seeking for tangled answers in an islescape of stories, this approach seeks to take the royal road from past to present, ignoring the terrain in between. As has long been the case with the mythic elements of maritime exploration, many writers have sought to explain Brendan's voyage as fact rather than myth. There has been a tendency to read the narrative of technology-driven exploration and discovery onto Brendan, to make Brendan a medieval Irish Columbus. Surely, dialectic demands, there must be a neat and 'real' history? Surely there must be a factual voyage, a kernel of objective reality?

Tim Severin (1978) — mentioned by Barron and Burgess — famously attempted to recreate Brendan's voyage in 1976-1977, sailing a hand-crafted 35-foot leather currach 4,500 miles from Ireland to Peckford Island, Newfoundland, in an attempt to verify the possibility of Brendan's legendary journey. A thrilling story to be sure, but a story that fails to entertain the possibility that Brendan's voyage was, as Flint puts it, 'one of pure imagination, constructed as an encouraging allegory of the voyage of the monk through the monastic life' $(1992,97)$. Out in the ocean, Brendan drifts in the sea of shared cultural transactions that globalize us all. To place him on the map, to historicize the events of the Nauigatio or the Voyage, is an expression of the very colonial attitude that the sea of islands approach hopes to modify.

\section{A More Commodious Ocean}


To embrace Hau'ofa, it is first necessary to place the European obsession with islands in the sea in context. The sea of islands is not a place for shaping, but for dwelling. It would be naïve-especially in the context of medieval literature - to ignore barriers, be they fear of the ocean, tales of its perils, or the discourse on the separateness of islands. The answer is, in keeping with our themed issue, to propose a new approach to British insularity, a vision of the British Isles and their fellows as nodes of production in a rich global system of cultural forces that shape and mingle, shift and flow, where literary separation does not create cultural separation. We can still treat discourses of separation and alienation with respect and highlight their contradictions. Expressions of insular desire, be it a desire to connect or a desire to divide, are part of a larger complex. Time is no barrier, ideas long past mingling with progressive thinking in tidalectic ebbs and flows.

Islands are what the powerful and powerless alike imagine them to be-community or prison, node or hermitage - and the oceans that separate archipelagos can be barriers in a physical or psychological sense but are a medium of transmission in cultural terms. Inspired by the scholarship of Hau'ofa, DeLoughrey, McCusker and Soares, and other key scholars of postcolonial insularity mentioned in this essay, an awareness of insular connectivity across time, culture, and genre complements and enhances existing notions of connectivity, enlivening our vision of European insularity. Rhetorical expressions of isolation or separation, distance and proximity, cry out for connection, for a shared oceanic identity.

By putting aside the Western notion of the insular, the sea of islands emerges. The knowledge it imparts is not totalizing or complete for, as Jeffrey Cohen has put it, 'Current-crossed and relentless, the froth and flux of oceans bear shipwreck, effacement, a bare record of receding wakes, a cobbled fleet of appositions, words and things' $(2015,134)$. It is, moreover, a sea of tropes beyond insularity, and it is a place where medievalists can be at home and form communities with other literary cultures at the littoral zones of the world. The isles can never be part of 'the continent,' always floating in a liminal state of escape and embrace, yet the mystery of separation titillates literary imaginations to such a degree that they are forever caught in the web of literary attention. How can this contradiction be 
resolved? The answer is that it need not be resolved, for it never existed in the first place - the rhetoric of separation is a cherished component of cultural intimacy.

What is visible when the literary ocean becomes commodious, spanning space and time? The answer is only possible via a Hau'ofa-esque shift in insular mentality: we see that the encircling ocean holds identity as much as its isles, for the sea remembers what time and Empire forgets, what received insular wisdom severs. Britain and its literary culture have long struggled with this contradiction, an archipelago apart, yet intimately connected to the continent—and the wider world — through bonds of identity, history, and culture. The physical isolation of the British Isles has shaped them, yet so has the commodious connecting membrane of the ocean. Its stories-the Brendan legend being a notable exemplar-teach us to be culturally at home in the imagining of the ocean even when the physical practicalities of its vast and often alienating mass discourage connection.

\section{About the Author}

James L. Smith focuses on intellectual history, medieval abstractions and visualization schemata, environmental humanities, and water history. He has also written on the themes of new materialism, the history of the senses, medieval maps and diagrams, medievalisms, and water management. His first book, entitled Fluid Models of Thought in Twelfth-Century Western Monasticism: Water as Medieval Intellectual Entity, is expected in 2017. He is a Research Associate at the University of York Centre for Medieval Studies (Email: james.1.smith@york.ac.uk).

\section{References}

Abu-Lughod, J. 1989. Before European Hegemony: The World System A.D. 1250-1350. Oxford: Oxford University Press. 
Barron, W.R.J. and Burgess, G.S. 2002. The Voyage of Saint Brendan: Representative Versions of the Legend in English Translation. Exeter: University of Exeter Press.

Cohen, J.J. 2015. The Sea is a Conveyance-Machine. In Oceanic New York, ed. Steve Mentz, 132-141. Brooklyn, NY: punctum books.

DeLoughrey, E.M. 2007. Routes and Roots: Navigating Caribbean and Pacific Island Literatures. Honolulu: University of Hawai'i Press.

Flint, V.I.J. 1992. The Imaginative Landscape of Christopher Columbus. Princeton, NJ: Princeton University Press.

Gillis, J.R. 2007. Islands in the Making of an Atlantic Oceania, 1500-1800. In Seascapes: Maritime Histories, Littoral Cultures, and Transoceanic Exchanges, eds Jerry H. Bentley, Renate Bridenthal and Kären Wigen, 21-37. Honolulu: University of Hawai’i Press.

Gillis, J.R. 2009. Islands of the Mind: How the Human Imagination Created the Atlantic World. New York: Palgrave Macmillan.

Goldie, M.B. 2011. Island Theory-The Antipodes. In Islanded Identities: Constructions of Postcolonial Cultural Insularity, eds Maeve McCusker and Anthony Soares, 1-40. Amsterdam and New York: Editions Rodopi.

Grafetstätter, A. 2011. Editor's Preface. In Islands and Cities in Medieval Myth, Literature, and History: Papers Delivered at the International Medieval Congress, University of Leeds, in 2005, 2006, and 2007, eds Andrea Grafetstätter, Sieglinde Hartmann and James Michael Ogier, 7-8. Frankfurt am Main: Peter Lang.

Hau'ofa, E. 1993. This Sea of Islands. In A New Oceania: Rediscovering Our Sea of Islands, ed. Eric Waddell, Vijay Naidu and Epeli Hau'ofa, 2-16. Suva: School of Social and Economic Development, USP, 1993. 
Horden, E. and N. Purcell. 2000. The Corrupting Sea: A Study of Mediterranean History. Oxford: Blackwell.

Hsy, J. 2013. Trading Tongues: Merchants, Multilingualism, and Medieval Literature. Columbus, $\mathrm{OH}$ : Ohio State University Press.

Jane, C., ed. 1988. The Four Voyages of Columbus: A History in Eight Document, Including Five by Christopher Columbus, in the Original Spanish, with English Translations. New York: Dover Publications.

Mack, J. 2011. The Sea: A Cultural History. London: Reaktion Books.

Matthews, A. 2016. The Ends of Polemic and the Beginning of Lohengrin. In Polemic: Language as Violence in Medieval and Early Modern Discourse, ed. Almut Suerbaum, George Southcombe and Benjamin Thompson, 43-64. Oxford: Routledge.

Pinet, S. 2011. Archipelagos: Insular Fiction from Chivalric Romance to the Novel. Minneapolis: University of Minnesota Press.

Severin, T. 1978. The Brendan Voyage: The Seafaring Classic That Followed St. Brendan to America. Dublin: Gill \& Macmillan.

Shell, M. 2014. Islandology: Geography, Rhetoric, Politics. Redwood City: Stanford University Press.

Sobecki, S.I. 2003. From the désert liquide to the Sea of Romance: Benedeit's Voyage de saint Brandan and the Irish immrama. Neophilologus 87, 193-207.

Sobecki, S.I. 2008. The Sea and Medieval English Literature. Woodbridge: D.S. Brewer.

Sobecki, S.I. 2011. Introduction: Edgar's Archipelago. In The Sea and Englishness in the Middle Ages: Maritime Narratives, Identity, and Culture, ed. Sebastian I. Sobecki, 1-30. Woodbridge: D.S. Brewer. 
Strijbosch, C., T. Summerfield, trans. 2000. The Seafaring Saint: Sources and Analogues of the TwelfthCentury Voyage of Saint Brendan. Dublin: Four Courts Press. 